\title{
An Empirical Study on Schema Theory in Listening Teaching of English Majors
}

\author{
Yueqing Wang ${ }^{1}$ \\ ${ }^{1}$ English department, Nan Yang Institue of Technology, Nanyang city \\ 53855477@qq.com
}

Keywords: Schema Theory, Listening Teaching, Teaching Experiment

\begin{abstract}
Listening comprehension plays a key role in verbal communication. Moreover, the traditional approach of listening comprehension teaching only stays at sentence level, so it is of less value to improve the students' listening ability, which determines that it becomes the research object of many disciplines. Plenty of studies have been conducted to examine listening from the neurological perspective, psychological perspective and pragmatic perspective, but they can not resolve all the problems in listening comprehension because of the limitations of the theories. Schema theory in discourse analysis creates a new perspective for listening comprehension research.
\end{abstract}

\section{Introduction}

Listening skill, as one of the most important and fundamental skills in language teaching, is the most frequently used language skill in our daily life. However, the present listening teaching is not satisfying. This kind of teaching method focuses on the result of listening rather than the process of listening. In this way, what the learners learn differs little from what they get from intensive reading or extensive reading class. Their listening comprehension ability has not been improved as much as what has been expected. So a reform of listening teaching is imperative under the situation.

In my thesis, I just try applying schema theory to listening teaching with the aim to improve listening teaching quality.

\section{Theoretical Framework}

Schema Theory. According to Carrell (1984), schema can be basically categorized into three types: linguistic schema (language knowledge), formal schema (rhetoric knowledge) and content schema (topic knowledge), which plays an important role in the process of listening comprehension.

Linguistic schema, which is also known as language schema, refers to linguistic knowledge, that is, the knowledge of phonetics, vocabulary, phrase, paragraph, sentence structure, grammar, and discourse and other linguistic knowledge. Linguistic knowledge plays an important role in listening comprehension, which is the base for listening comprehension. Only a listener masters enough language knowledge and quite a number of listening skills, can he possess the basic ability to activate his relevant schema and decode the listening material.

Formal schema, often known as textual schema, refers to "rhetorical organizational structures of different types of texts" (Carrell \& Eisterhold, 1983:79). Therefore, different types of texts have different organizational structures. The readers' familiarity with these organizational structures constitutes their formal schema. Formal schema is described as abstract, encoded, internalized, coherent patterns of media-linguistic, and textual organization that guide expectations in listeners' attempts to understand a meaningful piece of language.

Content schema, which refers to people's background or world knowledge about the topic, provides people with a foundation, a basis for comprehension (Carrell \& Eisterhold, 1983). It may include general cultural knowledge, topic familiarity, and previous experience with a field, specific knowledge on a given topic. If a listener are unfamiliar with or lacks certain cultural background 
knowledge, he can't activate related content schema even if he had enough linguistic schema. The more content schema the listener has, the more accurate his understanding is.

Approaches to Schema Theory in Listening Comprehension. Cognitive theory suggests that effective processing of discourse requires the use of both top-down and bottom-up processing. Schema theory also believes the process of listening comprehension is an interaction of both top-down and bottom-up processing.

The bottom-up listening process "involves knowledge of language system that allows the listener to segment and interpret the acoustic signal as sounds that form words, words that form phrases or clauses with a unifying intonation contour, and phrases or clauses that form cohesive and coherent texts such all levels of language analysis come into play" (CelceMatcia, 1999:364). According to Rost (2002). In bottom-up processing, listeners first attend to individual phonological units, then to a larger unit of input in hierarchical order, from vocabulary to structures, and finally arrive at the meaning of the discourse. Listening is a process of decoding the sounds that one hears in a linear fashion, in which meaning itself is derived as the last step in the process. This approach suggests building the sentence bit by bit in our mind, putting sound into words, words into phrases, and phrases into a whole sentence. In this model, linguistic schema plays an important role.

The alternative is the top-down model of listening. In this approach, the listener actively constructs (or more accurately, reconstructs) the original meaning of the speaker using incoming sounds as clues. In this reconstruction process, the listener uses prior knowledge of the context and situation within which the listening takes place to make sense of what he or she hears. That is to say, top-down listening processes involve activation of schematic knowledge and contextual knowledge. In this approach, listener rather than the text is the center of the listening process. In this model, formal schema and content schema schema play an important role.

In many instances where reduced speech or imperfect acoustic processing might obscure a message, an effective listener is able to use the situational context and/or the preceding and following discourse to disambiguate or to decide on the best interpretation. For example, the speaker says:

[eg.1] I'm lookin'fer Joe'n Barney. H've ya seen'm?

The effective listener will process " $\mathrm{m}$ " as them rather than him given the prior mention of two people: Joe and Barney. Whether the speaker is native or non-native, there must be sufficient information in the situation or co-text to process the acoustic signal properly.

Moving on to top-down processing, I offer the following example, which is to provide the listeners with a useful organizer:

[eg.2] "Today we're going to consider three forces that helped to shape the Carolingian Empire. We'll look at religion, we'll look at the prevailing social structure, and we'll consider economic factors."

With these opening words, the speaker has verbally established the following topic or main idea for his lecture: Three forces helped shape the Carolingian Empire. The speaker then lists the three forces on the board-each of which we now know will be discussed during the lecture.

1. religion; 2. social structure; 3. economic factors.

The L2 listener who has comprehended the opening statement (i.e. the topic) and its relationship to the list (which is in effect an outline) is in a much better position to understand and take notes on the lecture than the L2 listen who has missed the opening information about the topic. By grasping the three main points, listeners can use their stored schema to predict what will happen next.

The above examples show that both types of processing are useful and necessary for effective listening comprehension.

\section{Teaching Experiment}

The experiment is carried out to test whether schema theory is effective in English listening teaching. The author selected eighty English majors from two classes in my university as the subjects. Class 1 is experimental class (EC) and class 2 is control class (CC). The teaching material is Listen To 
This:1, published by Foreign Language Teaching and Research Press. Scholastic time is from February, 2010 to June, 2010.

Experiment Method. This experiment investigates the important role of schema theory in listening comprehension by both quantitative and qualitative methods.

Experiment Process. The specific teaching procedures for the experimental class and control class are different.

The teaching procedure for control class is carried out in traditional way, focusing on the acquisition of linguistic knowledge.

For the experimental class, the teacher adopted schema theory into the listening teaching process, focusing on the development of students' listening ability as well as their linguistic competence.

The Results of the Experiment. The data of the experiment are analyzed by the Statistical Package for the Social Sciences (SPSS). The independent samples test is to compare the difference between the two groups.

The pretest is to make a comparison of mean value between two independent samples, including the samples of experimental group and control group and carry out a test of hypothesis (two-side t-test). See Figure 2.1.

Pre-conditions of t-test. Firstly, each sample should be in normal distribution. A normal distribution test is applied to check if the data in both samples are in normal or abnormal distribution. With the SPSS software, a diagram of proportion-proportion plots is used to demonstrate this result. As shown in Figure 2.1, all the data points are placed in the same line, which sufficiently indicates data of the two samples are both in normal contribution.

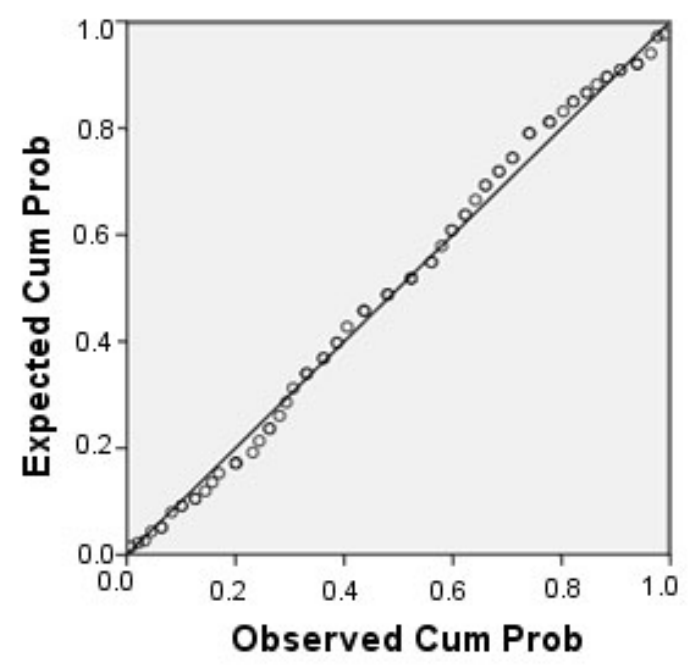

Figure 2.1 Normal P-P Plot of Score in Pretest

Secondly, two samples should have homogeneity of variance. T-test is adopted to find out whether the data satisfy this precondition. In this case, sig $=0.929>0.05$, which represents a homogeneity of variance. See Table 1 and Table 2. 
Table 1 Pretest : Group Statistics

\begin{tabular}{|c|c|c|c|c|}
\hline Class & N & Mean & Std. Deviation & Std. Error Mean \\
\hline Control & 40 & 64.2250 & 13.23842 & 2.09318 \\
\hline Experiment & 40 & 64.4750 & 13.00293 & 2.05594 \\
\hline
\end{tabular}

Table 2 Pretest : 2 Independent Samples Test

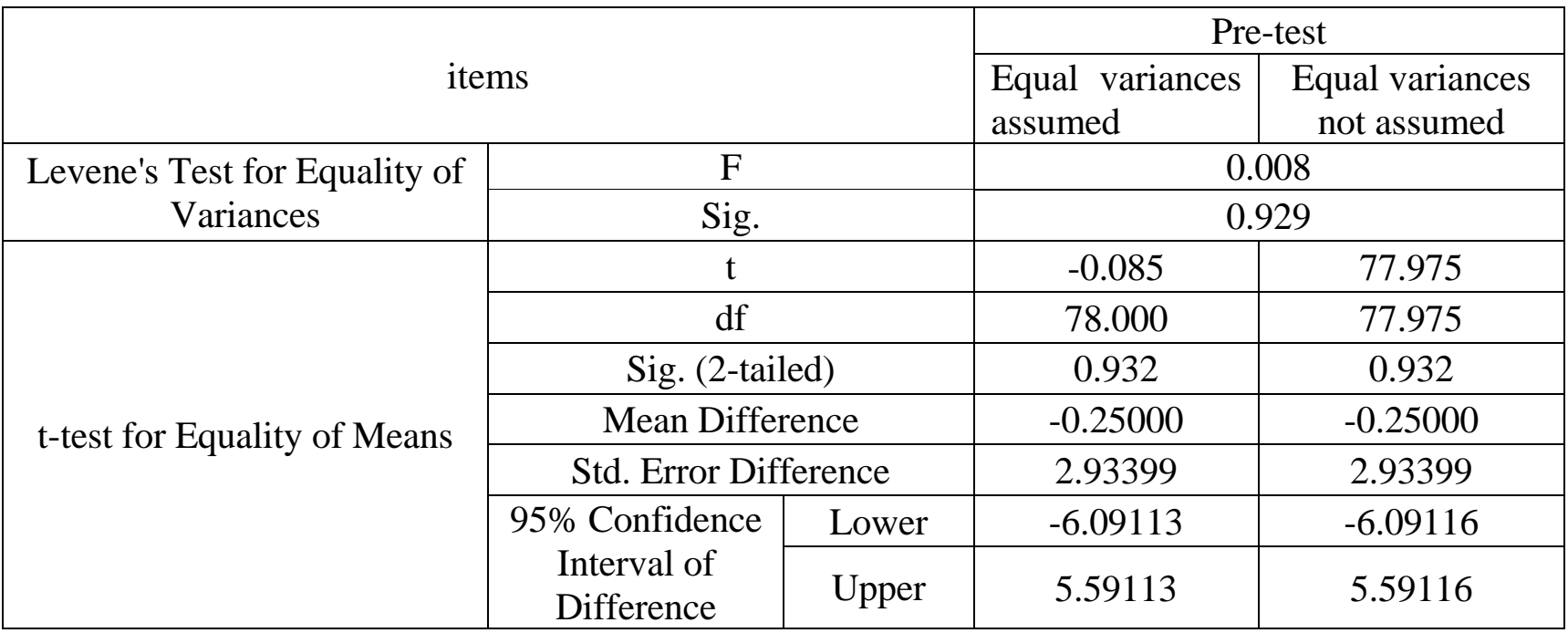

T-test to compare means of the two independent samples.

H0: No difference exists between the means of two samples

H1: Difference does exist between the means of two samples

The criteria of test: 0.05

Satisfying the two pre-conditions of t-test, the data of those two samples can be analyzed with the t-test. According the calculation by SPSS, in this pretest, Sig. (2-tailed) $=0.932>0.05$ (see Table 2). Therefore, H0 is confirmed, which means there is no distinct difference in test scores between the experimental class and the control class and the students' listening comprehension of both classes share a similar level. What's more, 95\% Confidence Interval of the Difference includes zero, which also means no difference exists between the means of two samples.

This pretest clearly indicates that the students share a similar listening comprehension level, which means the following experiments and data analysis can be conducted on an almost identical base so that it is possible to compare the results of the following tests after each experimental stage. The score distribution of the pretest can be shown clearly in Figure 2.2.

From the figure, we may see that the students in experiment class and control class share a similar listening comprehension level.

On post-test. In order to give a more concrete evidence, a post test is also conducted to the students in experimental and control groups, so it will provide us a more clear view on the effect of schema theory on listening comprehension, especially under the comparison with the pre-test results.

As the necessary procedure, in this post-test, the test score data from experimental and control groups are also given a normal distribution test. As shown in Fig.2.3, all the data points are placed in the same line, which sufficiently indicates data of the two samples are both in normal contribution. 


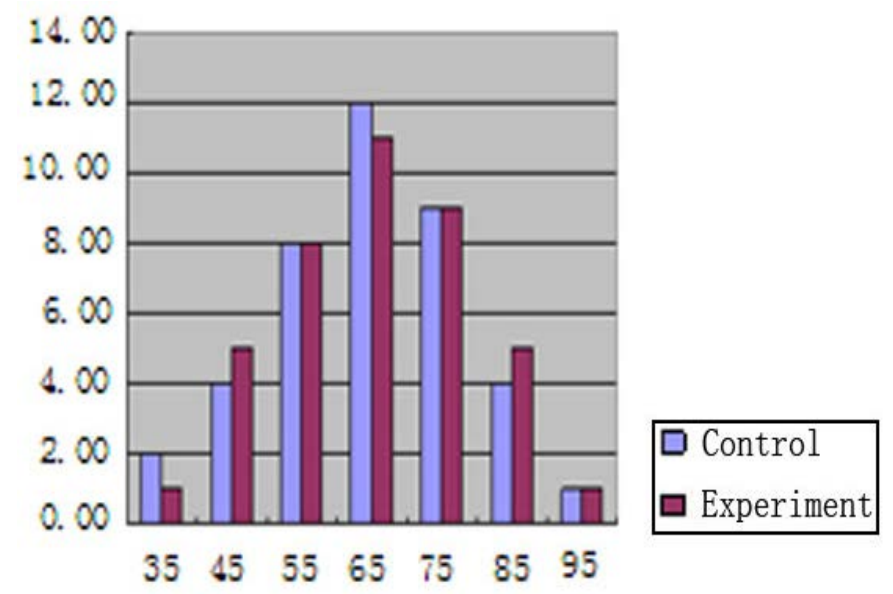

Figure 2.2 The score distribution of the pretest

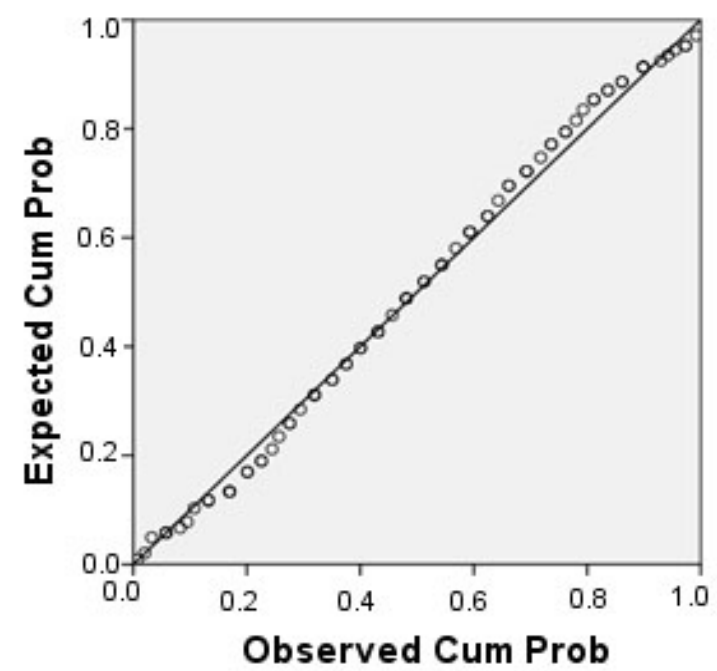

Figure2.3 Normal P-P plot of score in post-test

Then according to the T-test applied in this post test, sig $=0.923>0.05$, which represents a homogeneity of variance. See Table 3 and Table 4:

Table 3 Post-test : Group Statistics

\begin{tabular}{|c|c|c|c|c|} 
Class & $\mathrm{N}$ & Mean & Std. Deviation & Std. Error Mean \\
\hline Control & 40 & 65.1750 & 12.61234 & 1.99419 \\
\hline Experiment & 40 & 71.5750 & 12.63266 & 1.99740 \\
\hline
\end{tabular}


Table 4 Post-test : 2 Independent Samples Test

\begin{tabular}{|c|c|c|c|c|}
\hline \multirow{2}{*}{\multicolumn{3}{|c|}{ items }} & \multicolumn{2}{|c|}{ Pre-test } \\
\hline & & & \multicolumn{2}{|c|}{$\begin{array}{c}\text { Equal variances not } \\
\text { assumed }\end{array}$} \\
\hline \multirow{2}{*}{$\begin{array}{c}\text { Levene's Test for } \\
\text { Equality of } \\
\text { Variances }\end{array}$} & \multicolumn{2}{|c|}{$\mathrm{F}$} & \multicolumn{2}{|c|}{0.009} \\
\hline & \multicolumn{2}{|c|}{ Sig. } & \multicolumn{2}{|c|}{0.923} \\
\hline \multirow{7}{*}{$\begin{array}{l}\text { t-test for } \\
\text { Equality of } \\
\text { Means }\end{array}$} & \multicolumn{2}{|c|}{$\mathrm{t}$} & -2.268 & -2.268 \\
\hline & \multicolumn{2}{|c|}{$\mathrm{df}$} & 78.000 & 78.000 \\
\hline & \multicolumn{2}{|c|}{ Sig. (2-tailed) } & 0.026 & 0.026 \\
\hline & \multicolumn{2}{|c|}{ Mean Difference } & -6.40000 & -6.40000 \\
\hline & \multicolumn{2}{|c|}{ Std. Error Difference } & 2.82248 & 2.82248 \\
\hline & \multirow{2}{*}{$\begin{array}{l}\text { 95\% Confidence } \\
\text { Interval of } \\
\text { Difference }\end{array}$} & Lower & -12.01912 & -12.01912 \\
\hline & & Upper & -0.78088 & -0.78088 \\
\hline
\end{tabular}

According the calculation by SPSS, Sig. (2-tailed) $=0.026<0.05$. Therefore, H1 is confirmed, which means there is meaningful difference in test scores between the experimental group and the control group. In table3, it can be seen obviously that the mean of scores of experiment class (71.5750) is much higher than the mean of scores of control class (65.1750). Hereafter, the discourse analysis theories can improve learners' listening comprehension if they are properly used in their listening process.

The score distribution of the pretest can be shown in Figure 2.4.

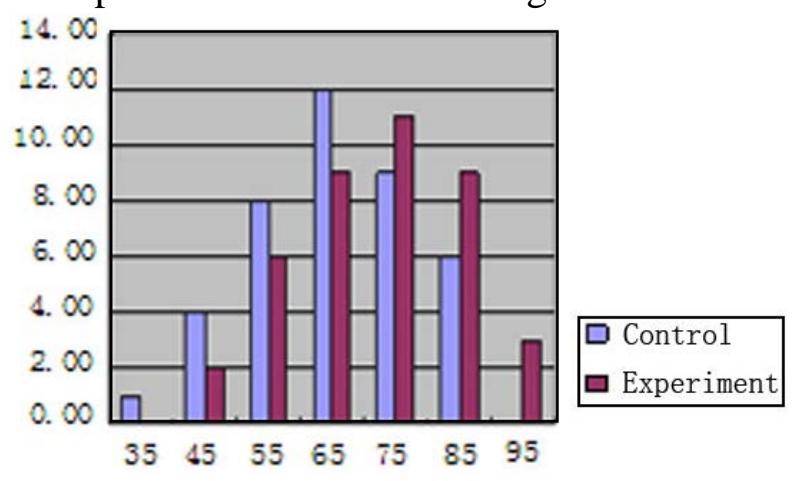

Figure2.4 The score distribution of the posttest

From the above figure, we may see that the scores of students in experiment class are much higher than that of control class, which reflects that the experiment is successful.

The Results of the Structured Interview. This part is concerned about the results of the researchers' interviews with some typical students, among whom 5 were the highest score achievers and 5 the lowest score achievers in the post proficiency test. The interviews with 10 students were carried out around the following 3 questions:

1. What is your feeling for this new teaching method?

2. Is such kind of method beneficial to your English learning?

3. Are you willing to go on with such method in the later regular English listening class?

As for the first question, most of the students reported their positive attitude towards strategy training and agreed on the effectiveness of this teaching method to some extent. But some of the lowest score achievers said that they can't use this method effectively because of the lack of the background knowledge of listening materials.

With regard to the second question, most of the students believed that this teaching method could facilitate their learning more or less. 
For the last question, most of the students expressed their willingness to accept such teaching method in the future.

In summary, most of the students believed that the new teaching could facilitate their listening comprehension.

\section{Pedagogical Implications of Schema Theory in English Listening Teaching}

As discussed in the previous sections, we can find out that schema theory plays a crucial role in learners' listening comprehension level. On account of this, the author will give further suggestions as for the various activities adoptable to improve their discourse analysis awareness during the respective three stages of listening processes(pre-listening, while-listening and post-listening) so as to improve their listening abilities to a desirable level.

Pre-Listening Activities. The pre-listening stage is the preparation stage for while-listening stage. Usually, students are confronted with two main obstacles in the listening process-linguistic one and non-linguistic one. In order to remove these obstacles away, one suggestion the author gives is to increase the storage of the schema. That is the accumulation of background knowledge and linguistic knowledge, which coincides with the content schema and formal schema as discussed in one area of the discourse theories above. At this stage, the appropriate activities for learners should include the following aspects:

The teacher provides some warming-up activities and motivation in order to arouse students' interest and activate their schema. It is essential for the students to take an active role before listening and to be motivated to the greatest degree so that they can be psychologically prepared for the listening tasks they are going to undertake. This can be realized by following activities:

Firstly. Give students a topic to discuss or design some appropriate pre-listening questions which are related to listening material and students are interested in.

Secondly. Make full use of multi-media. Projector, computer, scanner, and video presenter sometimes will achieve satisfactory results in listening comprehension.

If the students are not familiar with background knowledge, the teacher should provide necessary cultural background knowledge in order to help students construct new schema.

The teacher provides students with necessary linguistic knowledge. It is desirable that teachers should set aside three or five minutes to train students to get familiar with certain important phonological as well as grammatical cues. Since listening is not totally guess-work, students do need some helpful and necessary acoustic information in the text to confirm the comprehension. If the listening material involves some difficult and complicated sentences, the teacher can also explain them in advance.

Firstly, the teacher should focus on training students' pronunciation and intonation and correct their mistakes whenever they have in order to improve their abilities of recognizing different sounds. Such basic knowledge includes differences between British English and American English pronunciations, phonetics change phenomena. Instructions concerned with this aspect should include pronunciation, intonation, redundancy and loss of explosion. Furthermore, the teacher can expose the students to tape-recordings of different discourse types and original English films or videos at regular times to make them familiar with authentic pronunciation, intonations, and rhythms and let the students imitate the native sounds at any moment.

Secondly, the teacher should give students sufficient grammatical drills and help them grasp frequently-used sentence patterns such as indicating a causal relationship, comparison, suggestion, request and the subjunctive mood. What's more, the students should keep in mind some fixed expressions closely related to a certain place, setting, profession or identity.

While-Listening Activities. The teacher's role in while-listening stage is to help learners develop the skill of eliciting messages from spoken language, to assist concentration and to guide the listeners through the text. During this phase the teachers is virtually unable to intervene too much. Meanwhile, teachers should carefully design appropriate activities. 
At this stage, discourse analysis is mainly carried out to see how an idea is developed. The teacher should organize some activities to develop students’ listening skills:

Make predictions. Making prediction is the ability to anticipate before and during listening what one is going to hear. Clues for making predictions include contexts, co-text and visual input. Students tend to listen more purposefully and attentively when they make predictions because they want to find out if they have predicted correctly. They can understand the passage well and pay more attention to the sentences which are more difficult to understand.

Listen for gist. It means to listen for main ideas or for the "big picture". Listening as the listener listens to get a general idea and not focus on supporting details. Experts say that this is the skill listeners employ most frequently.

Listen selectively. When given a passage, students should be trained to detect which part or slot in more important and then students can listen selectively and pay more attention to the important part. This ability help students to listen in a more relaxed manner.

Draw inference. It is the ability to fill in gap in the input. Sometimes speakers leave information out because they assume the listeners already know it or they are being deliberately ambiguous. This requires the listener to listen "between the lines". A listener may also miss some parts of the speech because of fatigue, noisy surroundings, etc. A schema contains many slots. Once certain slots in a schema are filled with text information, other slots become easier to be filled in.

Of course, not all the activities are adopted in one passage. According to different listening material, the teacher will choose different method.

Post-listening Stage. So far, comprehension of the listening discourse may seem to be completed and learners tend to stop at this stage. In fact, post-listening stage is an indispensable part of the teaching of listening, but often neglected. Then it is the teacher's responsibility to push the learners a step forward, for example, to encourage them to form their own evaluative viewpoint. Moreover, the post-listening activities must be intrinsically motivating.

At this stage the students have time to think, to discuss, and to write. Meanwhile, they should also be given a learner-learner interaction period, during which they can work cooperatively in small groups to check their predictions and supposition by negotiating meanings and exchanging opinions. In this way, they can learn from each other and enjoy their pleasure in real communication with their peers.

The frequently-used activities at this stage are role-play, report, form/chart completion, sequencing/grading, extending notes into written responses, summarizing, identifying relationships between speakers, establishing the mood/attitude/behavior of the speaker.

At the end of this stage, the teacher should make sure to give necessary feedback to learners' performance. Their problems are summarized and tackled by reviewing the difficult parts while newly-taught skills and strategies are to be reinforced by encouraging learners to apply them to their after-class practice. Note that it is very necessary for the teacher to assign students listening tasks after class, because the more they listen, the better they will eventually improve their listening proficiency.

To sum up, the post-listening stage is an extension of the pre-listening stage and while-listening stage. It not only winds up the current lesson, but also serves as a preliminary introduction to a new lesson.

\section{Conclusion}

This thesis is an attempt to introduce schema theory into our classroom practice aiming at realizing teaching listening comprehension in its real sense and helping transform students from a passive and vulnerable over-hearer to an active and ready searcher for meanings in the process of listening. After one-term teaching of new method, the students from the experimental class make much greater progress than those from control class, which proved the new method is fairly effective in facilitating students' listening comprehension. This paper only explores the possibility of somehow manipulating schema theory and instructions in class for better performance and strategy 
development on the part of students. In this sense, the attempt is a rather tentative and unfulfilled one to demonstrate the pedagogical implication of discourse analysis on listening.

\section{References}

[1] Anderson, A \& Lynch, T. 1988. Listening. Oxford: Oxford University Press.

[2] Anderson, R. C. \& Pearson. P. D. 1984. A schema-theoretic view of basic processes in reading comprehension. In P. Pearson (Ed). Handbook of Reading Research. New York: Longman.

[3] Byrnes, H. 1984. The role of listening comprehension: theoretical base. Foreign language annals: 17, 317-329.

[4] Buck, G. (1995). How to become a good listening teacher. In D. J. Mendelson, \& J.Rubin (Eds.), A guide for the teaching of second language listening. San Diego, CA: Dominie Press.59 -73.

[5] Carrell, P.L. \& Eistenhold, J.C. 1983. Schema theory and ESL reading pedagogy .TESOL Quarterly (17): 553-573.

[6] Morley, J. 1991. Listening Comprehension in Second/Foreign Language Instruction. In M. Celce Murcia (Eds.), Teaching English as A Second Or Foreign Language. Boston: Heinle\&Heile, 81-106.

[7] Richards, J.C. 1983. Listening Comprehension: Approach, design, procedure. TESOL Quarterly,17 (2).

[8] Rost, M. 1990. Listening in language learning. New York: Longman. 